\title{
SAGA CIGANA: NARRATIVAS (AUTO) BIOGRÁFICAS INTERGERACIONAIS NA COMUNIDADE DO BAIRRO SUMARÉ NO MUNICÍPIO DE SOBRAL-CE
}

\author{
SAGA GITANA: NARRATIVAS (AUTO) BIOGRÁFICAS \\ INTERGENERACIONALES EN LA COMUNIDAD DEL BARRIO SUMARÉ EN \\ EL MUNICIPIO DE SOBRAL-CE
}

\section{SAGA GYPSY: INTERGENERATIONAL (AUTO) BIOGRAPHICAL NARRATIVES IN THE COMMUNITY OF THE SUMARÉ NEIGHBORHOOD IN THE MUNICIPALITY OF SOBRAL-CE}

Liana Liberato Lopes CARLOS ${ }^{1}$

Andrea Abreu ASTIGARRAGA ${ }^{2}$

RESUMO: Quem são, como vivem, o que pensam os integrantes de várias gerações ciganas? O que sabemos sobre eles são transmitidos por eles mesmos ou pelo filtro do preconceito, da discriminação e do estigma? Em que medida o diálogo intercultural permeia a visão que a sociedade tem da comunidade cigana? Este artigo descreve e analisa três narrativas autobiográficas intergeracionais ciganas compostas por uma família organizada em pai, filha e tio, que serão denominados de: SOL, LUA e ESTRELA, respectivamente. A comunidade cigana em estudo está situada no Bairro Sumaré, no município de Sobral, no Ceará. As narrativas orais foram coletadas em forma de entrevistas semiestruturadas. O principal resultado da pesquisa nos revela que a comunidade cigana ainda vive envolta no preconceito, na estigmatização. Percebemos, na pesquisa que, a comunidade faz sua história para enfrentar as situações de estigma e exclusão sócio-cultural, com atitudes de resistências, mantendo seus costumes e jeito de ser. Por fim, compreendemos que ouvir a comunidade cigana, suas vozes, para servirmos como amplificadores de suas resistências, possibilita manter e recuperar suas identidades culturais, no que diz respeito às suas origens.

PALAVRAS-CHAVE: Ciganos. Estigma. Interculturalidade. Narrativas intergeracionais.

RESUMEN: ¿Quiénes son, como viven, lo que piensan los integrantes de varias generaciones gitanas? ¿Qué sabemos sobre ellos son transmitidos por ellos mismos o por el filtro del prejuicio, la discriminación y el estigma? ¿En qué medida el diálogo intercultural permea la visión que la sociedad tiene de la comunidad gitana? Por lo tanto, este artículo describe y analiza tres narraciones autobiográficas

\footnotetext{
${ }^{1}$ Universidade Federal do Ceará (UFC) - CE - Brasil. Doutoranda em Educação. Atualmente integra os grupos de pesquisas do CNPq: Grupo de Estudos e Pesquisas Autobiográficas-GEPAS -(UVA-CE) e Oralidade, Cultura e Sociedade- (UECE). Estar vinculada ao Centro Universitário-UNINTA como professora. Pesquisadora da CAPES no Programa de Formação de Professores (PARFOR) junto ao curso de Pedagogia da Universidade Estadual Vale do Acaraú- (UVA-CE). E mail: lianallopes@ hotmail.com.

${ }^{2}$ Universidade Estadual Vale do Acaraú (UVA) - CE - Brasil. Professora Adjunta. Coordenadora do Grupo de Estudos e pesquisas autobiográficas - GEPAS. E-mail: astigarragaandrea@yahoo.com.
}

RPGE- Revista on line de Política e Gestão Educacional, Araraquara, v.21, n. esp.2, p. 1016-1030, nov. 2017. 
intergeneracionales gitanas compuestas por una familia organizada en padre, hija y tio, que serán denominados: SOL, LUNA y ESTRELLA, respectivamente. La comunidad gitana en estudio está situada en el Barrio Sumaré, en el municipio de Sobral, en Ceará. Las narraciones orales fueron recogidas en forma de entrevistas semiestructuradas. El principal resultado de la investigación nos revela que la comunidad gitana todavía vive envuelta en el prejuicio, en la estigmatización. En la investigación que la comunidad hace su historia para enfrentar las situaciones de estigma y exclusión sociocultural, con actitudes de resistencias, manteniendo sus costumbres y la forma de ser. Por último, comprendemos que escuchar a la comunidad gitana, sus voces, para servir como amplificadores de sus resistencias, posibilita mantener y recuperar sus identidades culturales, en lo que se refiere a sus Orígenes.

PALABRAS CLAVE: Gitanos. Estigma. Interculturalidad. Narrativas intergeneracionales.

ABSTRACT: Who are, as they live, what the members of several gypsy generations think? What do we know about them are transmitted by themselves or by the filter of prejudice, discrimination and stigma? To what extent does intercultural dialogue permeate society's vision of the Roma community? Therefore, this article describes and analyzes three autobiographical intergenerational gypsy narratives composed by a family organized in father, daughter and uncle, that will be denominated of: SUN, MOON and STAR, respectively. The gypsy community under study is located in the Sumaré neighborhood, in the municipality of Sobral, Ceará. Oral narratives were collected in the form of semi-structured interviews. The main result of the research reveals that the gypsy community is still involved in prejudice, stigmatization. We realize in the research that the community makes its history to face situations of stigma and socio-cultural exclusion, with attitudes of resistance, maintaining their customs and way of being. Finally, we understand that listening to the gypsy community, their voices, to serve as amplifiers of their resistance, makes it possible to maintain and recover their cultural identities, with respect to their origins.

KEYWORDS: Gypsies. Stigma. Interculturality. Intergenerational narratives.

\section{Introdução}

Não podemos iniciar esse artigo sem antes destacar a relevância das pesquisas com os ciganos no campo da educação. Haja vista que as referidas pesquisas no âmbito educacional ainda carecem de um debate mais promissor e instigante. Entendemos a educação como um processo de socialização, de movimento heterogêneo, de diferenças e similitudes, ou seja, como um processo de reconhecimento constitutivo da diversidade cultural.

Por essa razão, trazemos para o cerne do nosso debate as narrativas intergeracionais ciganas, uma vez que, as pesquisas com pessoas desta comunidade 
legitimam, ressignificam e recompõem socialmente a nossa história, a nossa cultura, as nossas raízes, os nossos costumes e nossa identidade enquanto povo brasileiro constituídos de uma diversidade linguística e de uma composição e mistura de raças. Nesta premissa, os ciganos fazem parte do nosso mundo, e, todavia, são distintos da maioria de nós; portadores de certos complexos culturais que os individualizam e os distinguem das culturas nacionais não-ciganas. Sendo assim, podemos dizer que, enquanto sujeitos construtores da história, também estamos imersos em um pluralismo cultural.

Nessa esteira de pensamento, este artigo traz à baila um diálogo de aproximação com a comunidade cigana para analisar por meio de suas narrativas (auto) biográficas seus modos de vida em diferentes épocas e perceber o que permaneceu e o que mudou dentro da comunidade. Contudo, o diálogo com os ciganos de três gerações nos permite de modo patente estar conectado em mundos culturais diferentes. Ancorado no pensamento de Passeggi (2014) as narrativas (auto) biográficas são fontes de investigação e método de pesquisa que se assentam no pressuposto do reconhecimento e da legitimidade de vários sujeitos, tais como, crianças, adolescentes, adultos, etc. Autores como Ricouer (2007), Goffman (1998), Goldfarb (2013), Nunes (1996), Hilkner (2008), Bauman (2004), vêm ao encontro das questões que permeiam esta discussão e servem como fundamento para as reflexões que desenvolveremos ao longo deste trabalho.

\section{Caminho metodológico}

Metodologicamente, adotou-se a abordagem qualitativa, uma vez que ela oportuniza, à luz de um contexto e um dado espaço temporal, a concatenação do objeto de estudo com a compreensão e a análise dos fatos. O método das narrativas (auto) biográficas e da História Oral, apresentam-se como o caminho mais adequado à natureza do problema investigado, aos seus objetivos à subjetividade das fontes e à flexibilidade da pesquisa (TRIVIÑOS, 2012).

Para Passeggi (2010), a pesquisa (auto) biográfica em Educação toma como objeto de estudo as fontes biográficas e autobiográficas, considerando-as como método de pesquisa, práticas de formação e modos de narrar a experiência vivida. Nessas diferentes direções, o humano é colocado no centro da investigação-formação, acreditando-se nele e em suas potencialidades reflexivas de se voltar para si mesmo 
como sujeito de sua história. Os estudos propõem-se a examinar os modos como os indivíduos dão forma à experiência vivida, no processo permanente de construção de sua história pessoal e da história social, focalizando a interação dialética entre o espaço social (público) e espaço pessoal (privado). Para realizar tal investimento, explora-se o entrelaçamento entre linguagem, pensamento e práxis social.

A História Oral é um método visto como um conjunto de procedimentos, uma prática de apreensão de narrativas, e constituiu-se numa possibilidade de estudo da sociedade por meio de depoimentos gravados e transcritos.

A pesquisa empírica foi conduzida levando-se em conta os seguintes critérios: uma família cigana representada por três gerações distintas o tio, o pai e uma filha que vivenciaram diferentes contextos sociais na comunidade cigana do Bairro Sumaré em Sobral- CE. Os entrevistados serão aqui denominados de: SOL, LUA e ESTRELA.

Para a coleta de dados realizaram-se três entrevistas semiestruturadas, pois esta possibilita iniciar-se a partir de pontos básicos correlatos à investigação e que, posterior, possibilita alargar a seara de interrogativas, produto de novas hipóteses que vem à lume à proporção que se colhem as respostas do entrevistado (TRIVIÑOS, 2012).

A coleta de dados foi realizada durante três dias seguidos. Sendo um dia dedicado a cada sujeito da pesquisa. A entrevista semiestruturada contou com as seguintes questões: Como se dá a educação cigana? O que faz o cigano para manter a tradição? Como os ciganos mais velhos educam as crianças? E mais, o que os ciganos pensam sobre a escola? Cada entrevista durou em torno de uma hora. Após, realizamos a transcrição, categorização e análise a partir do acervo teórico do tema em estudo.

\section{Contextualizando o debate}

Vivemos numa sociedade desigual onde a discriminação cultural, econômica, política e étnica, toma contornos e avança de forma acelerada atingindo todos os espaços sociais. Por vezes marginalizamos e isolamos os diferentes, chegamos a excluir os que não pensam e se comportam com nós. Desenvolvendo o conceito de Estigma, Goffman define que:

Enquanto o estranho está a nossa frente podem surgir evidências de que ele tem atributo que torna o diferente dos outros que se encontram numa categoria em que pudesse ser incluído, sendo, até, de uma espécie menos desejável - num caso extremo, uma pessoa completamente má, perigos ou fraca. Assim, deixamos de considerá-lo 
criatura comum e total, reduzindo-o a uma pessoa estragada e diminuída (1998, p. 12).

Logo, compreende-se que a sociedade estabelece meios de categorizar as pessoas e os atributos considerados normais, aceitáveis e comuns; e os indivíduos que não se encaixam em tais categorias são considerados menos desejáveis. Assim, quando há um descrédito em relação aos indivíduos ou grupos sociais, dizem que estes possuem um estigma, por essa razão, passam a possuírem desvantagens sociais, que coincidem com os estereótipos desenvolvidos para identificar tais indivíduos.

Os ciganos estão inseridos em um grupo historicamente estigmatizado em todas as esferas sociais. "Eles são pouco contemplados pelas políticas públicas, pois têm, mais do que os outros grupos, dificuldade em se organizar para reivindicar direitos diante do Estado" (SILVA, 2015, p. 45).

A constante perseguição dos ciganos pela Europa e no Brasil ainda não se encerrou. Partindo das reflexões de Goldfarb (2013) podemos apontar que, um dos indicativos dos estigmas em torno dos ciganos, faz parte das nossas representações coletivas desde os tempos coloniais persistindo até os dias atuais. Segundo a autora, a imagem negativa dos ciganos foi disseminada em livros, revistas, jornais e explorada pela impressa midiática. Instituídos como errantes, que vivem da mendicidade e do furto, além de permanecerem no imaginário social revestido por uma imagem folclorizada: as mulheres sensualizadas com seus vestidos coloridos e rodados, anéis, brincos; os homens em seus muares e lenços amarrados na cabeça. Os ciganos que vivem na periferia, nos acampamentos, são reconhecidos como perigosos e ferem a boa conduta da civilização.

É necessário frisar que os estigmas interferem nas relações sociais e estão relacionados às representações coletivas dos sujeitos. As representações que se tem dos ciganos referem-se a elementos depreciativos passando a ser nocivo e incapaz dos parâmetros impostos pela sociedade. Na esteira de Chartier (1990, p. 42):

As representações sociais e identitárias se expressam a partir dos comportamentos e práticas de socialização pelas quais os indivíduos constroem e dão sentidos às suas existências e ao mundo social. Embora assumindo uma posição isolada ou invisibilizada da sociedade, os ciganos, ao mesmo tempo assumem papeis fundamentais na sociedade não cigana, pois colaboram estabelecendo uma referência entre as duas e demarcam assim as diferenças no amplo contexto social. 
Para Levi-Strauss (1983, p. 58): “[...] as comunidades fechadas, tradicionais ou frias são aquelas baseadas em costumes, tabus e rituais que determinam os modelos de conduta a seguir". Assim, reconhecemos os ciganos como grupos sociais que fazem parte das comunidades fechadas e habitualmente se opõem às sociedades contemporâneas. Com base nos estudos de Nunes (1996, p. 87): “[...] as comunidades ciganas sentem-se ameaçadas pelo ostracismo a que foram votados ao longo da história". E, por essa razão, consideram a sociedade não cigana hostil, opondo-se a ela por um processo de aculturação, ou seja, perda ou transformação dos traços culturais originários.

Frente ao avesso do Eu e do Outro, encontramos diferenças e similitudes, formando um continente social, amplo, plural e diversificado. É na convivência com o outro que o ser humano se insere nas mais diversas esferas sociais, levando consigo a cultura do seu povo, o que significa que: “[...] quanto mais conhecemos a nós mesmos, tanto mais estamos habilitados a compreender o outro" (RICOUER, 2007, p. 23).

Diante dessa realidade, lembramos que os ciganos são povos que vivem à sombra da sociedade, reconhecidos como grupos sociais vulneráveis e em risco de exclusão. Possuidores de hábitos linguísticos e culturais diferenciados dos demais grupos sociais, foram denominados de bruxos e condenados pela igreja católica; perseguidos e massacrados durante a segunda guerra mundial, na mira do ódio nazista foram vitimados pelos arianos de Hitler. "Mesmo enfrentando as resistências de exclusão da sociedade não cigana, esses grupos se colocam como grupos que fazem sua história, que fundamenta o seu povo, uma vez que ela é comum a todos os seus membros" (CARLOS, 2015, p. 34).

\section{Cultura dos povos ciganos e a possibilidade de um diálogo intercultural}

Vivemos numa sociedade caracterizada pela necessidade de nos relacionarmos num contexto cada vez mais multicultural e heterogêneo. Temos de um lado, a pressão homogeneizadora e, do outro, a incerteza sobre a própria identidade. No entanto, sensibilizar as pessoas para diversidade cultural exige uma mudança de atitude. Os quatro princípios de uma educação de qualidade definidos no Relatório da Comissão Mundial sobre Educação para o século XXI, nos possibilita oferecer respostas para um diálogo intercultural. Dentre os quatro pilares da educação: aprender a aprender; 
aprender a conhecer; aprender a fazer; e aprender a conviver; destacamos o aprender a conviver para fortalecer o debate em discussão, uma vez que, esse princípio da educação é um fio condutor importante para as aprendizagens participativas e para a educação intercultural.

Logo, estudar a cultura cigana é um empreendimento ambicioso, pois se constitui em uma prática polissêmica, além de oferecer uma resposta aos desafios do diálogo intercultural traz diversas possibilidades de interpretação. Guiados pelo pensamento de Sandra Jatahy Pesavento (2005, p. 67): “[...] um novo olhar acerca dos povos ciganos nos envolve quando nos colocamos a pensar na cultura como um conjunto de significados partilhados e construídos pelos homens para explicar o mundo em que vive".

As culturas são produzidas pelos grupos sociais ao longo das suas histórias, na construção de suas formas de subsistência, na organização da vida social e política, nas suas relações com o meio e com outros grupos, na produção de conhecimentos. A diferença entre culturas é fruto da singularidade desses processos em cada grupo social (BRASIL, 1997, p. 121).

No Brasil, não existe nenhuma legislação especificamente cigana. No entanto, a Constituição Federal de 1998 relata alguns artigos que diz respeito as minorias ciganas garantindo aos ciganos nascidos no Brasil os mesmos direitos dos outros cidadãos. $\mathrm{O}$ Art.216. refere-se ao patrimônio material e imaterial tomados individualmente ou em conjunto, portadores de referência à identidade, à ação, à memória dos diferentes grupos formadores da sociedade brasileira, nos quais incluem: a)as formas de expressão; b)os modos de criar, fazer e viver; c)as criações científicas, artísticas e tecnológica.

A Organização das Nações Unidas para a Educação, Ciência e Cultura reconhece como patrimônio cultural imaterial as expressões de vida e tradições que comunidades, grupos e indivíduos recebem de seus ancestrais e passam seus conhecimentos a seus descendentes. Para muitas pessoas, especialmente as minorias étnicas, o patrimônio imaterial é uma fonte de identidade e carrega a sua própria história.

Dessa forma é necessário investir na diversidade cultural e no diálogo intercultural com as comunidades ciganas e valorizar suas tradições favorecendo aproximação entre as culturas ciganas e não ciganas. Reconhecer e respeitar as diferentes formas de conhecimento e os modos de expressão, os costumes e tradições de 
um povo, facilita o diálogo e permite o livre arbítrio de expressão. Por conseguinte, o diálogo intercultural exige o empoderamento de todos os participantes e requer a interação, sem a perda da identidade pessoal ou coletiva.

Historicamente, a cultura cigana faz parte de um universo complexo, rico e dinâmico. Na tradição cigana os ensinamentos são transmitidos por meio da oralidade, os mais velhos ensinam os mais novos. Os elementos da natureza têm suas representatividades, como: o fogo, a água, a terra e o ar que despertam distintos níveis de energia. O elemento fogo representa sensualidade, viva no amor, da harmonia e calor humano, a água lava e limpa a vida e os livra de toda carga negativa, traz alegria e bem estar, a terra evoca prosperidade, sobrevivência, força e equilíbrio, o ar representa o sopro mágico da vida, as das energias físicas e da saúde (HILKNER,2008). Além da diversidade de cores, adereços, música, dança crenças e rituais que compõem esse mosaico cultural.

O modo de ver o mundo, as apreciações de ordem moral e valorativa, os diferentes comportamentos sociais e mesmo as posturas corporais são explicados pela história cultural de cada grupo. Assim, “[...] entendemos o fato de que indivíduos de culturas diferentes como os ciganos são identificados por suas características culturais" (LARAIA, 1999, p. 87).

$\mathrm{O}$ autor ainda nos revela como a cultura influencia o comportamento social e diversifica o homem, destaca que a nossa herança cultural é desenvolvida por meio de diferentes gerações e sempre nos condicionou a reagir depreciativamente em relação ao comportamento daqueles que agem fora dos padrões aceitos pela maioria da comunidade. Por isso, discriminamos o comportamento de pessoas diferentes de nós.

Vale ressaltar que a influência da cultura cigana teve suas repercussões em outras culturas, por exemplo, na Espanha, a tradição da música e da dança cigana deu origem ao Flamenco. "Cabe destacar que o Flamenco surgiu com a retomada cristã da península Ibérica e com o advento do Tribunal da Inquisição por volta de 1478, quando os judeus e ciganos buscavam refúgio nas montanhas e passaram a viver com os camponeses pobres" (MAIA, 2013, p. 34). É uma dança de origem espanhola e tem seu ritmo derivado da mistura cultural de outros povos. Para os ciganos a dança é uma força de expressão da vida que demonstra a forma de viver com liberdade, o trabalho autônomo representa também sua liberdade, haja vista que são povos que não obedecem às leis do Estado e possuem seus próprios códigos de vida em suas comunidades. 


\section{Narrativas (auto) biográficas intergeracionais dos ciganos do Bairro Sumaré}

O que faz parte de nós mesmos e que pode estar ali adormecido como uma tatuagem nos possibilita lembrar a cada dia da sua existência (THOMPSON, 1992, p. 65).

Tomando como base a epígrafe acima, busca-se dar vozes e visibilizar os ciganos do Bairro Sumaré como sujeitos protagonistas que mesmo enfrentando um cenário social marcado pela marginalização, exclusão, estereótipo e indiferença, não deixam de expressar o que pensam, o que sabem a respeito de suas crenças, valores e costumes.

Nessa toada, apresenta-se aqui, as narrativas intergeracionais de uma família cigana representadas por três gerações distintas: o tio, o pai e uma filha, pois os mesmos vivenciaram momentos distintos dentro da comunidade. Dessa forma é possível compreender em suas narrativas a estigmatização e preconceito que os ciganos vivem, além de compreender como se configura processo de interculturalidade e ruptura cultural na comunidade cigana do Bairro Sumaré.

\footnotetext{
Nos meados do século XX, a comunidade cigana do Bairro Sumaré iniciou o seu processo de sedentarização, o qual foi ocasionado pelas transformações que regiam o mundo a partir da ideia de progresso, tal visão era dramática revelando- se como um acúmulo de catástrofes, dessa forma passaram a conviver numa sociedade marcada pela desigualdade e conflitos sociais, o qual caracterizavam os indivíduos portadores da cultura nômade, como forasteiros e, em determinados momentos, como classe perigos (CARLOS, 2016, p. 45).
}

Ao ouvir as narrativas intergeracionais dos ciganos do Bairro Sumaré, não podemos fazer um divisor de águas, pois ao mesmo tempo que interpretamos algumas apropriações simbólicas culturais em detrimento à cultura letrada, também analisamos comportamentos, valores, sentimentos, emoções; captamos a vida cotidiana dos ciganos em seus ritmos variados permitindo que os mesmos expressem o que pensam, o que sentem e o que sabem sobre si e sobre o mundo que lhe rodeia. "As narrativas, culturalmente herdadas, possuem uma estrutura convencional, no entanto, aberta e flexível, já que podem ser configuradas e reconfiguradas no ato de narrar" (BROCKMEIER \& HARRÉ, 2003, p. 78), é possível perceber na fala de Sol quando nos revela que: A vida cigana é uma vida boa porque o cigano vive de troca, ler mão, 
bota baralho, o cigano legítimo não deixa a tradição de carta, búzio, da leitura da mão essa é a vida cigana atendendo e ajudando o próximo (CIGANO SOL).

Ao mesmo tempo em que o narrador relata sobre sua vida, justifica a ação relatada revela um emponderamento da representação de si. Ao usar em sua fala a expressão "ajudar ao próximo", percebe-se o respeito pelo o outro, dessa maneira, constata-se que o estar no mundo é conviver ao mesmo tempo com as diferenças e semelhanças, o que significa respeitar a singularidade de cada um, pois: "[...] é o valor das diferenças que enriquece o mundo no qual se vive" (BAUMAN, 2004, p. 98).

Nesse sentido, as narrativas dos ciganos nos possibilitam o rompimento com o estranho, ao mesmo tempo, que passamos a entender o homem no seu construto social independente de suas crenças, atitudes e valores compartilhados socialmente. "É nesse ponto que as narrativas tornam-se uma ferramenta preciosa para o acesso às construções que os sujeitos fazem a respeito do que se passa em suas vidas, para assim, entendermos a subjetividade humana e sua complexidade" (PASSEGGI, 2010, p. 56).

Embora esquecidos e frente aos caminhos dispersos que a vida ofereceu aos ciganos, os mesmos não deixam de expressar seus desejos e sentimentos. Quando o destino lhes apresenta novos rumos, como uma poeira encrustada pelo tempo e na busca pelos seus direitos para manter viva suas tradições, Lua nos revela o seu sonho

\footnotetext{
O meu sonho é chegar até o prefeito pra que ele desse aqui numa área mais central, assim tipo uma casa, uma casa nem que seja pequena com dois ou três cômodos. Não pra mim, é pra gente montar uma escola sobre a comunidade cigana em Sobral, que é pra repassar pras pessoas botar uns aparato que desse certo filmagem, foto (CIGANO LUA).
}

Como já citado anteriormente, a educação cigana é transmitida pela oralidade, ou seja, os mais velhos ensinam os mais novos, no entanto, os fios da narrativa de Lua, aponta que o que une a comunidade são as características ancestrais, como por exemplo, a conservação da oralidade como processo educativo. É possível perceber a preocupação do narrador para dar seguimento aos costumes que o grupo traz como marca identitária, no caso o dialeto.

De acordo com o Cigano Lua:

A função dos mais velhos é repassar os ensinamentos, sua cultura (dança), suas crenças (leitura das mãos, jogo de búzios e leitura de cartas de baralho), como também aconselhar os mais jovens, que atualmente além de dispersos, estão cada vez mais se afastando de 
suas origens, pois hoje dentro da comunidade há uma junção de ciganos puros com não puros, onde muitas vezes não há um entendimento perfeito, surgindo uma preocupação por parte das lideranças temendo assim a extinção dos ciganos, vale ressaltar que essa extinção se dá pela ausência das características ancestrais desse grupo (CARLOS, 2016, p. 32)

A narrativa de Lua é compreendida como relevante para entendermos o processo da ruptura cultural por parte dos mais jovens, ao mesmo tempo que, indiretamente, elabora o discurso de pertencimento e de responsável pela educação das crianças e dos jovens. Sempre que fala das atuais gerações, seu olhar vagueia pelo espaço ao mesmo tempo em que a voz parece faltar, pois segundo o mesmo,

As novas gerações não cultivam os hábitos e costumes, como usar roupas compridas, não dançam e principalmente não aceitam o comprometimento dos casamentos arranjados pelos pais, não utilizam o dialeto egipciano, e não valorizam a leitura das mãos (CIGANO LUA).

"O ato de narrar possibilita a compreensão das ações e intenções de seres humanos inseridos num mundo físico e sociocultural" (BROCKMEIER \& HARRÉ, 2003, p. 96). Sabe-se que desde a infância somos capazes de refletir sobre o que nos acontece.

É na infância que tomamos a consciência com conformação ou deformação e damos um novo sentido aos acontecimentos e a nós mesmos. As crianças incorporam, interpretam e reconstroem continuamente informações culturais, constituídas por valores, normas sociais, ideias, crenças e representações sociais (SARMENTO, 2005, p. 52)

Ao narrar sobre sua infância, Estrela, afirma que:

A minha infância foi boa, a minha mãe ficava com a gente, mas o meu pai saía pra botar cartas, jogar búzios, viajava para Bacabal Maranhão e outros lugares, aí ele trazia mantimentos pra gente, trazia dinheiro, ouro dos outros lugares, as pessoas que mesmo davam porque nada dessas coisas é tomado (CIGANA ESTRELA).

Frente ao exposto percebe-se que as crianças ciganas em relação à sua cultura são ativas desde pequenas, nesse sentido significa dizer que os papeis desempenhados por elas na família acontecia em meio às atividades cotidianas, através de um ensino natural. Era uma educação pragmática voltada para o aprendizado das habilidades e 
comportamentos necessários à educação da criança e do jovem, sendo única e igual para todos.

Para Aranha (2006), as primeiras comunidades que desenvolveram os sistemas de educação se basearam inicialmente na tradição, perpetuando valores e comportamentos através das gerações, principalmente nas sociedades ágrafas. A autora ainda comenta que: "[...] em tais sociedades os mitos e os ritos são transmitidos oralmente e a tradição se impõe por meio da crença permitindo a coesão do grupo e a repetição dos comportamentos desejáveis" Aranha (2006, p.35), o que nos lembra a educação cigana.

Sabemos que os pais agem como os primeiros formadores dos vínculos criançamundo, fornecendo-lhe as regras, as instruções, os itinerários formativos de base - a educação cigana não se dá de forma diferente. No entanto ao entrar na escola, a criança cigana enfrenta um choque cultural onde as práticas aprendidas por elas no seio familiar tornam-se insignificantes. É possível perceber nesta fala: "Já cheguei a trabalhar no centro com o meu pai, mas eu vi que aquilo não era pra mim, devido eu ter estudado, eu desaprendi muita coisa, mas eu tentei manter a minha tradição (CIGANA ESTRELA)".

A partir do depoimento da cigana Estrela percebemos que a escola ainda se encontra alheia à cultura cigana, no entanto torna-se necessário nos questionar constantemente sobre: qual o papel da escola, e qual a sua função na sociedade e natureza das suas práticas numa cultura em mudança, no caso a cultura cigana? Neste sentido a escola torna-se insignificante para a criança cigana pois enquanto instituição social que comporta diversos saberes e que transmite conhecimentos ainda permanece omissa em cumprir seu papel sociocultural com os ciganos.

\section{Considerações finais}

Thompson (1992), em seu livro A Voz do Passado, nos faz lembrar que "a história oral é uma história construída em torno de pessoas", as fontes orais são mais do que fontes, são a prova da identidade de um povo, assim o trabalho debate basicamente a legitimidade dessa identidade, que na sociedade moderna passam de verídica à duvidosa, e muito se perdem com o tempo.

O debate conceitual proposto por Passeggi (2010, p. 34), “[...] o método das narrativas (auto) biográficas se fortalece à medida que conduzimos os indivíduos para expressarem o que pensam, o que sabem e o que sente sobre suas vidas". Com efeito, os 
ciganos da comunidade do Sumaré nos revelam um campo de luta contra a situação de exclusão e esquecimento. Frente ao exposto, os excluídos só têm o estigma de excluídos quando não nos lembramos deles, os ciganos do Bairro de Sumaré em Sobral, já não são mais excluídos porque agora falamos em nome deles onde quer que estejamos.

Em linhas finais, salientamos que as pesquisas com os ciganos nos permite uma visão ampla, na medida que percebemos os conflitos e o entrecruzamento cultural existente dentro do grupo.

\section{REFERÊNCIAS}

BAUMAN, Z. Amor Líquido: sobre a fragilidade dos laços humanos. Trad. Carlos Medeiros. Rio de Janeiro: Jorge Zahar Editor, 2004.

BRASIL. Presidência da República. Secretaria Especial dos Direitos Humanos. Povo cigano: o direito em suas mãos. Brasília, DF: Presidência da República, 2007.

BRASIL. Secretaria de Educação Fundamental. Parâmetros Curriculares Nacionais: pluralidade cultural, orientação sexual/secretaria de educação fundamental. Brasília: MEC/SEF,1997.

BROCKMEIER, Jens.; HARRÉ, Rom. Narrativa: problemas e promessas de um paradigma alternativo. Psicologia: Reflexão e Crítica, v. 16, n. 3, p. 525-535, 2003.

CARLOS, Liana Liberato Lopes.; CAVALCANTE, Maria Juraci Maia. O passado como um Presente mais ou menos invisível: as memórias dos ciganos assentados no Bairro Sumaré em Sobral-Ceará. In: CONGRESSO DE HISTÓRIA DA EDUCAÇÃ̃ NO CEARÁ, 14, 2015, Crato. Comunicação oral. Crato: URCA, 2015.

CARLOS, Liana Liberato Lopes. Memória, Cultura e Tradição: Trajetória Histórica dos Ciganos em Sobral-Ceará (1974-2000). Dissertação de Mestrado. Programa de PósGraduação em Educação. Universidade Federal do Ceará, Fortaleza, 2016.

CHARTIER, Roger. História cultural: entre práticas e representações. 2 ed. Lisboa: DIFEL, 1990. (Coleção memória e sociedade).

GOFFMAN, Erving. Estigma: notas sobre a manipulação da identidade deteriorada. Tradução de Márcia Bandeira de M. L. Nunes. Rio de Janeiro: LTC, 1988.

GOLDFARB, Maria Patrícia Lopes. Memória e etnicidade entre os calons de Sousa. João Pessoa: Editora UFPB, 2013.

HILKNER, Regiane Aparecida Rossi. Ciganos: peregrino do tempo- ritual, cultura e tradição. Tese de Doutoramento, Campinas - São Paulo, 2008. 
LARAIA, Roque de Barros. Cultura: um conceito antropológico. 24 ed. Rio de Janeiro: Zahar, 1999.

LÉVI-STRAUSS, Claude. O pensamento selvagem. Rio de Janeiro: Zahar, 1983.

MAIA. Simone Brilhante. A dança cigana como prática artística pedagógica.

Disponível em:

<https://monografias.ufrn.br/jspui/bitstream/123456789/1290/1/Maia_Simone_Brilhant e.pdf $>$. Acesso em: 24 ago. 2015.

NUNES, Olímpio. O povo cigano. 2 ed. Lisboa: Artes Gráficas; Águeda, 1996.

PASSEGGI, Maria da Conceição. Narrar é humano! Autobiografar é um processo civilizatório. In: PASSEGGI; Silva (Org.). Invenções de vidas, compreensão de itinerários e alternativas de formação. São Paulo: Cultura Acadêmica, 2010. p. 103130.

PESAVENTO, Sandra Jatahy. História e história cultural. 2 ed. Belo Horizonte: Autêntica, 2005.

RICOUER, Paul. A memória, a história, o esquecimento. Tradução de Alain François. Campinas: Editora da UNICAMP, 2007.

SARMENTO, Manuel Jacinto. Gerações e alteridade: interrogações a partir da sociologia da infância. Revista Educação e Sociedade, v. 26, n. 91. Campinas: Cedes, 2005.

SILVA, Lailson Ferreira da. Parentesco, relações sociais e estilo de vida entre os calons de Sobral, Ceará. 2015. Tese (Doutorado em Ciências Sociais) - Programa de Pós-Graduação em Ciências Sociais, Universidade Federal do Rio Grande do Norte, Natal, 2015.

THOMPSON, Paul. A voz do passado. Tradução Lólio Lourenço de Oliveira. Rio de Janeiro: Paz e Terra, 1992.

TRIVIÑOS, A. N. S. Introdução à pesquisa em ciências sociais: a pesquisa qualitativa em educação. 21. reimpr. São Paulo: Atlas, 2012.

UNESCO, Relatório Mundial da. Investir na diversidade cultural e no diálogo intercultural. Disponível em:

<http://unesdoc.unesco.org/images/0018/001847/184755por.pdf>. Acesso: em 27 jul. 2017. 


\section{Como referenciar este artigo}

CARLOS, Liana Liberato Lopes.; ASTIGARRAGA, Andrea Abreu. Saga Cigana: narrativas (auto) biográficas intergeracionais na comunidade do bairro Sumaré no município de Sobral-Ce. Revista on line de Política e Gestão Educacional, Araraquara, v. 21, n. esp. 02, p. 1016-1030, nov. 2017. Disponível em: <http://dx.doi.org/10.22633/rpge.v21.n.esp2.2017.10205>. E-ISSN:1519-9029.

Submetido em: 31/07/2017

Aprovado em: 06/09/2017 